\title{
BUDAYA LOKAL MALUKU “PELA GANDONG" DALAM KONTEKS PERILAKU ORGANISASI
}

\author{
Elsina Huberta Aponno \\ Politeknik Negeri Ambon, Jurusan Administrasi Niaga \\ E_Mail: elslatumaerissaponno@yahoo.com
}

\begin{abstract}
Abstrak: Penelitian ini bertjuan untuk memaknai budaya lokal Maluku "Pela gandong" dalam konteks perilaku organisasi. Budaya sebagai program mental pada sekelompok orang menjadi dasar bagi pembentukan kepribadian dari orang-orang dalam kelompok tersebut. Proses budaya mempengaruhi perilaku organisasi antara lain dengan cara karyawan membawa budaya mereka ke tempat kerja dalam bentuk kebiasaan dan bahasa yang juga mempengaruhi nilai-nilai individu, etika, sikap, anggapan, dan harapan. "Pela gandong" merupakan proses budaya sehingga dapat mempengaruhi kepribadian dan nilai-nilai individu seseorang di tempat kerjanya. Sistim kekerabatan yang dibangun berdasarkan nilai-nilai pela gandong diharapkan mampu mempengaruhi perilaku individu di tempat kerjanya.,
\end{abstract}

Abstract: This study aims to interpret the local culture of Maluku "Pela gandong" in the context of organizational behavior. Culture as a mental program to a group of people form the basis of the personality of the people in the group. The process of organizational culture influences behavior among others by employees bringing their culture into the workplace in the form of customs and language also affects the individual values, ethics, attitudes, assumptions, and expectations. "Pela gandong" is a cultural process that can affect the personality and values of the individual person in the workplace. Kinship system which is built upon the values itself reportedly expected to affect the behavior of individuals in the workplace.

PENDAHULUAN

Saat ini bidang manajemen sumber daya manusia mengalami banyak tekanan untuk melakukan perubahan. Pergeseran dalam ekonomi, globalisasi, keragaman tenaga kerja, dan teknologi telah menciptakan tuntutan baru untuk organisasi dan mendorong penelitian lapangan dalam beberapa arah yang benar-benar baru (Stone dan Deadrick, 2015). Tantangan mendesak bagi organisasi dengan karyawan berbeda latar belakang budaya adalah tenaga kerja yang beragam dalam mengahadapi globalisasi (White, 1999). Alih-alih struktur organisasi tradisional yang sangat bergantung pada pengendalian manajemen dan prinsip-prinsip ekonomi seperti pengurangan biaya, efisiensi, dan aliran uang tunai, fokus dalam organisasi modern adalah pada manajemen sumber daya manusia. Saat ini, organisasi mengharapkan karyawan menjadi proaktif dan menunjukkan inisiatif, berkolaborasi dengan lancar dengan orang lain, mengambil tanggung jawab untuk pengembangan profesional mereka sendiri, dan harus berkomitmen untuk mencapai kualitas tinggi dari standar kinerja yang ditetapkan (Bakker dan Schaufeli, 2008).

Perilaku organisasi merupakan sebuah bidang interdisipliner yang ditujukan untuk memahami dan mengelola pegawai dengan lebih baik. Artinya, perilaku organisasi berorientasi pada penelitian dan penerapan. Tiga tingkat dasar analisis dalam perilaku organisasi adalah individu, kelompok, dan organisasi (Kreitner dan Knicki, 2014). Kajian-kajian perilaku organisasi menunjukan bahwa ada interaksi timbal balik dari setiap tingkatan. Reaksi yang diberikan individu ternyata tidak selalu sama walaupun diberikan 
stimulus yang sama dari dinamika kelompok ataupun sistim organisasi karena adanya perbedaan-perbedaan individu. Dua individu sering bertindak dengan sangat berbeda dalam situasi yang sama, dan perilaku individu yang sama mengalami perubahan dalam situasi yang berbedabeda (Robbins dan Judge, 2014). Hal ini membuat perilaku organisasi terus menjadi topik yang menarik untuk dikaji karena semakin banyak referensi yang dimiliki tentang bagaimana individu berperilaku akan mengembangkan teori-teori perilaku organisasi dan menjadi dasar pengambilan kebijakan oleh pihak manajemen.

Budaya menjadi salah satu hal yang menarik untuk ditelusuri lebih jauh dalam kajian perilaku organisasi. Tsui, et al., (2007) dalam meta analisisnya tentang perkembangan penelitian perilaku organisasi dengan budaya nasional sebagai variabel utama mengungkapkan sejumlah perkembangan paradigma dan metode penelitian yang digunakan, namun hal tersebut juga yang menjadi kesenjangan karena terjadi terutama di Amerika Utara dan Eropa, padahal abad 21 mestinya merupakan abad penelitian manajemen internasional. Tantangan unik dari penelitian perilaku organisasi dalam konteks lintas-nasional adalah untuk memastikan validitas konstruk konsep budaya, menyertakan pembeda nasional lainnya untuk meningkatkan validitas internal temuan, dan memperkuat desain penelitian dengan memanfaatkan kolaborasi antar negara sehingga mampu meningkatkan validitas eksternal.

Tsui, et al (2007) kemudian merekomendasikan agar lebih banyak penelitian dengan karakteristik negara lain dengan budaya yang berbeda dengan preferensi berdasarkan model yang sudah ada (yang sebagian besar adalah model Amerika Serikat) dan dianalisis dengan negara lain yang mungkin berbeda dari Amerika pada fenomena yang sama. Amerika Utara dan Eropa mendominasi literatur manajemen global sehingga Tsui, et al., (2007) mendorong penelitian lebih spesifik terutama dari negara-negara di Asia, Amerika Selatan, dan negara berkembang lainnya untuk mengisi kesenjangan dalam pengetahuan manajemen global. Hal ini sejalan dengan yang dikemukakan oleh Hosftede (1991), bahwa berdasarkan tingkat individualisme, Amerika yang berada pada peringkat satu dari 50 negara dengan skor IDV (individualism index) 91 memiliki karyawan dengan perilaku yang berbeda dengan karyawan Indonesia dan Pakistan yang berada pada peringkat 47 atau 48 dengan skor IDV 14. Peringkat tersebut menunjukan Amerika sebagai negara yang berkarakter individualism sedangkan Indonesia dikategorikan negara dengan nilai kolektifisme sehingga penelitian dengan menggunakan model budaya individualis Amerika tentu tidak akan cocok diterapkan di negara dengan nilai kolektif seperti Indonesia. Saat ini juga telah terjadi pergeseran dalam organisasi yang dinamis dari individu yang bekerja dalam tim kerja. Robbins (2006) menunjukkan bahwa kerja tim sulit kesulitan diterapkan oleh banyak karyawan di negara-negara Barat, karena mereka memiliki budaya individualistik dan lingkungan kerja di negara-negara Barat memiliki sifat kompetitif yang menghargai prestasi individu. Kerja tim diperkirakan lebih mungkin berkembang di negaranegara dengan nilai kolektivitas tinggi.

Dalam mempelajari budaya, dikenal juga konsep etnis yang sering digunakan bergantian 
dengan budaya dan ras. Biasanya, etnis digunakan dalam referensi untuk kelompok dengan kebangsaan, budaya, atau bahasa yang sama. Etnis mengacu pada kualitas etnis atau afiliasi dari kelompok, yang biasanya dicirikan dari segi budaya (Betancourt dan Lopez, 1993). Kelompok etnis cenderung berinteraksi dengan kelompok etnis lain, interaksi tersebut tidak boleh diabaikan karena mungkin merupakan sumber pengaruh budaya. Oleh karena itu, adalah penting bahwa studi banding dari kelompok etnis mengidentifikasi dan mengukur variabel budaya yang diasumsikan bertanggung jawab dalam perbedaan yang diamati dalam fenomena psikologis sebelum perbedaan tersebut dikaitkan dengan budaya atas dasar keanggotaan kelompok (Betancourt dan Lopez, 1993).

Etnis banyak digunakan dalam variabel penelitian perilaku dan hasilnya menunjukan bahwa etnis tertentu akan menunjukan perilaku yang berbeda dari etnis lainnya (Jean, 2013; Lam, et. al. 2002; Ngo, et. al. 2006; Ang, et. al, 2003). Pengaruh etnis terhadap gaya kepemimpinan ditemukan pada penelitian Jean (2013), yaitu bahwa gaya kepemimpinan pemimpin keturunan Amerika lebih konsisten dan tegas, sedangkan pemimpinan keturunan Amerika Asia lebih menekankan kesederhanaan, kerjasama, harmonisasi dengan lingkungan. Persepsi karyawan terhadap keadilan organisasi pada karyawan yang nilai individualisme tinggi maupun rendah cenderung tidak ada perbedaan (Lam et al. 2002), namun persepsi tentang keadilan bagi karyawan dengan jarak kekuasaan yang rendah lebih baik dibandingkan dengan yang jarak kekuasaannya tinggi. Ngo, et. al. (2006) membuktikan hipotesis penelitiannya dengan responden karyawan etnis China bahwa responden dengan tingkat verticalism yang tinggi mempunyai persepsi yang lebih baik tentang keadilan distributif dibandingkan dengan karyawan dengan tingkat verticalism yang lebih rendah. Ang, et. al. (2003) menemukan tidak ada perbedaan bagi karyawan etnis China yang tinggal di Singapura (karyawan lokal) dan yang hanya datang untuk bekerja (karyawan lokal) dalam persoalan keadilan prosedural, namun kayawan asing merasa mendapat perlakuan berbeda untuk keadilan distributif. Hubungan etnis dengan kinerja dibuktikan dalam penelitian Marimuthu dan Kolandaisamy (2009) tentang pengaruh etnis dan gender terhadap kinerja keuangan pada perusahaan di Malaysia. Hasil penelitian menunjukan keragaman etnis dari dewan pimpinan mempunyai korelasi yang signifikan dengan kinerja keuangan dan konsisten pada periode yang berbeda. Ang, et. al. (2003) juga menemukan bahwa karyawan asing mempunyai kinerja yang lebih rendah dari karyawan lokal di Singapura.

Indonesia sebaiknya juga banyak melakukan kajian-kajian perilaku dengan melibatkan etnis mengingat keragaman budaya dan etnis yang dimilikinya. Menurut Hofstede (1991), Indonesia dikategorikan sebagai negara dengan nilai-nilai kolektif. Walaupun beragam budaya dan etnis, secara umum memang nilai-nilai yang terkandung dalam budaya lokal di Indonesia mengandung nilai kolektifisme. Kambu et. al, (2012) dalam penelitiannya di Papua menunjukan bahwa budaya Papua dengan indikator etos kerja, gotong royong, keterbukaan, pelestarian budaya, dan pola 
konsumtif mampu meningkatkan kinerja melalui OCB.

Nilai-nilai kearifan budaya lokal Jawa juga telah digunakan untuk meneliti perilaku. Siswanto dan Najih (2015) mengemukakan bahwa budaya Jawa memiliki kearifan lokal yang sangat kaya dalam semua aspek kehidupan. Gotong royong, urun rembug, ataupun tepo seliro merupakan contoh kearifan lokal dari Jawa yang memiliki pengaruh moderat dalam berbagi pengetahuan sehingga kearifan lokal memiliki cukup pengaruh dalam keinginan berbagi pengetahuan sebagai dasar keberhasilan implementasi manajemen pengetahuan dalam masyarakat. Hudaya dan Nugroho (2013) menawarkan gaya kepemimpinan Hasta Brata sebagai pandangan baru terhadap pembelajaran kepemimpinan yang filosofis terhadap lingkungan internal dan eksternal organisasi yang bersifat dinamis.

Tri Hita Karana yang diartikan sebagai tiga penyebab kebahagiaan, kesejahteraan ataupun kemakmuran hidup manusia (Wirawan 2011 dalam Putera dan Supartha, 2013) yang merupakan unsur kebudayaan di Bali yang bersifat universal dan dinamis juga mampu mempengaruhi perilaku seseorang. Konsep Tri Hita Karana menurut Riana (2011) merupakan konsep harmonisasi hubungan manusia dengan Tuhan (parahyangan), hubungan antar manusia (pawongan), dan hubungan manusia dengan lingkungan (palemahan). Tri Hita Karana berpengaruh terhadap budaya organisasi (Putera dan Supartha, 2013), orientasi kewirausahaan dan orientasi pasar (Riana, 2011), keyakinan diri, keinovatifan personal, penggunaan sistim informasi akuntansi (Suardikha, 2012 dalam Putera dan Supartha, 2013).
Kearifan lokal lainnya yang turut mempengaruhi perilaku yaitu Siri'na Pacce yang merupakan pandangan hidup masyarakat Bugis Makassar. Konsep siri' memiliki dua kandungan nilai, yaitu nilai malu dan harga diri. Sementara pacce bermakna solidaritas sosial yang tinggi. Dalam studi kualitatif yang dilakukan Azis, et al (2015) nilai-nilai Siri'na Pacce digunakan untuk memaknai independensi auditor.

Dalam konteks budaya lokal, masyarakat Maluku khususnya di Maluku Tengah mempunyai tradisi "pela gandong” yang juga cukup kental mempengaruhi perilaku masyarakatnya. Pela sebagai pranata sosial masyarakat Maluku dapat memperlihatkan bagaimana leluhur masyarakat Maluku tanpa memandang atau mempertimbangkan perbedaan-perbedaan yang ada diantara mereka baik berupa perbedaan kultural, sosial maupun perbedaan religi dan agama (Uneputty, 1996). "Pela gandong” (Lokollo et al, 1997) merupakan perserikatan antara satu negeri di Pulau Ambon dengan satu atau beberapa negeri lain di Pulau Ambon, Lease dan Pulau Seram, perserikatan mana didasarkan pada hubungan sejati dengan isi dan tata laku perserikatan yang diatur dalam perjanjian baik lisan maupun tulisan, dimana para pihak berjanji untuk tunduk kepada perjanjian dimaksud sebagai dasar hukum bagi implementasinya dari waktu ke waktu.

Hubungan "pela gandong” ini mempunyai efek yang sangat penting dimana semua masyarakat turut serta menjunjung kebersamaan dan menjaga hubungan tersebut. Banyak kajian yang dilakukan mengenai "pela gandong" namun kebanyakan mengkaji dari aspek sosiologi 
antroplogi (Sahusilawane, 2004; Uneputty, 1996; Lokollo et al, 1997; Huwae, 1995; Pattiselano, 1999). "Pela gandong” juga banyak digunakan dalam kajian ilmiah namun lebih ditekankan pada fungsinya untuk mencegah ataupun menangani konflik (Ralahallo, 2009; Kadir, 2012; Manuhuttu, 2015; Frost, 2004; Mualim et al, 2014; Hoedodo et al, 2013), pembinaan masyarakat pasca konflik (Tuhuteru, 2014; Sholeh, 2013), pengembangan pembangunan (Piris dan Tilaar, 2014), ataupun pengintegrasiannya dalam metode pendidikan (Tuhuteru, 2014; Matitaputty, 2013). Pela gandong juga terbukti telah menjadi bidang kajian yang menarik tidak hanya bagi peneliti lokal (Sahusilawane, 2004; Uneputty, 1996; Lokollo et al, 1997; Ralahallo, 2009; Manuhuttu, 2015; Huwae, 1995, Pattiselanno, 1999) namun juga menjadi perhatian peneliti nasional (Hoedodo et al, 2013; Sholeh, 2013) dan internasional (Bartels, 1977 dalam Uneputty, 1996; Frost, 2004; Mualim et al, 2014).

Walaupun demikian, belum ada kajian manajerial pada aspek ini, padahal nilai-nilai yang terkandung dalam budaya (tentunya termasuk pela gandong sebagai budaya lokal) menurut Hosftede (1991) mampu mempengaruhi perilaku organisasi. Budaya memiliki elemen preskriptif dan deskriptif serta melibatkan asumsi spontan tentang bagaimana berpikir, bertindak, dan merasakan. Para karyawan membawa budaya mereka ke tempat kerja dalam bentuk kebiasaan dan bahasa. Budaya masyarakat dan budaya organisasi bekerja sama mempengaruhi nilai-nilai yang dianut seseorang, etika, sikap-sikap, dan harapan-harapan (Kreitner dan Kinicki, 2014). Hosftede (1991), mendefenisikan budaya sebagai program mental yang berpola pikiran (thinking), perasaan (feeling), dan tindakan (action) atau disebut dengan "software of the mind". Pemrograman mental atau budaya ini dikembangkan melalui suatu sistem nilai yang berkembang dalam masyarakat, kemudian sistem nilai ini akan menjadi normanorma sosial yang mempengaruhi perilaku sosial. Defenisi tersebut mengekspresikan bahwa budaya termasuk budaya lokal pela gandong turut mempengaruhi perilaku pelaku organisasi.

\section{BUDAYA DALAM PELAKU ORGANISASI}

Budaya telah diidentifikasi sebagai salah satu bidang kajian perilaku organisasi. Ilmu antropologi yang memberikan kontribusi terhadap hal ini (Robbins dan Judge, 2014). Analisis lintas budaya pun menjadi penting dilakukan untuk lebih memahami perilaku dalam organisasi.

Budaya merupakan seperangkat kepercayaan dan nilai tentang apa yang disukai dan tidak disukai dalam satu komunitas orang, serta seperangkat praktek formal dan informal untuk mendukung nilai-nilai. Budaya memiliki elemen preskriptif dan deskriptif serta melibatkan asumsi spontan tentang bagaimana berpikir, bertindak, dan merasakan. Budaya mengesampingkan ikatan nasional. Aspek-aspek kunci dari budaya masyarakat, seperti kebiasaan dan bahasa dibawa ke tempat kerja oleh individu. Budaya masyarakat dan budaya organisasi bekerja sama mempengaruhi nilai-nilai yang dianut seseorang, etika, sikap-sikap, dan harapan-harapan (Kreitner dan Kinicki, 2014). Hosftede (1991), mendefenisikan budaya sebagai program mental yang berpola pikiran (thinking), perasaan (feeling), dan tindakan (action) atau disebut dengan 
"software of the mind". Pemrograman mental atau budaya ini dikembangkan melalui suatu sistem nilai yang berkembang dalam masyarakat, kemudian sistem nilai ini akan menjadi normanorma sosial yang mempengaruhi perilaku sosial. Definisi tersebut mengekspresikan bahwa budaya turut mempengaruhi perilaku pelaku organisasi.

Hofstede (1991) mendefinisikan budaya sebagai pola pikiran, perasaan dan tindakan untuk kelompok-kelompok sosial, yang membedakannya dengan kelompok sosial lainnya. Konsep budaya diturunkan dari program mental yang dibedakan dalam tiga tingkatan, yaitu ; 1) Tingkat universal, yaitu program mental dimiliki seluruh manusia dan melekat pada diri manusia, 2) Tingkat kolektif, yaitu program mental dimiliki oleh beberapa, tidak seluruh manusia. Pada tingkat ini program mental khusus pada kelompok atau kategori dan dapat dipelajari. 3) Tingkat individual, yaitu program mental unik dimiliki oleh hanya seorang atau dua orang yang tidak akan memiliki program mental yang sama. Pada tingkatan ini program mental sebagian kecil melekat pada diri manusia, dan lainnya dapat dipelajari dari masyarakat, organisasi atau kelompok lain. Ketiga tingkatan ini dapat digambarkan sebagai berikut :

Gambar 1.

Tingkatan Program Mental Manusia

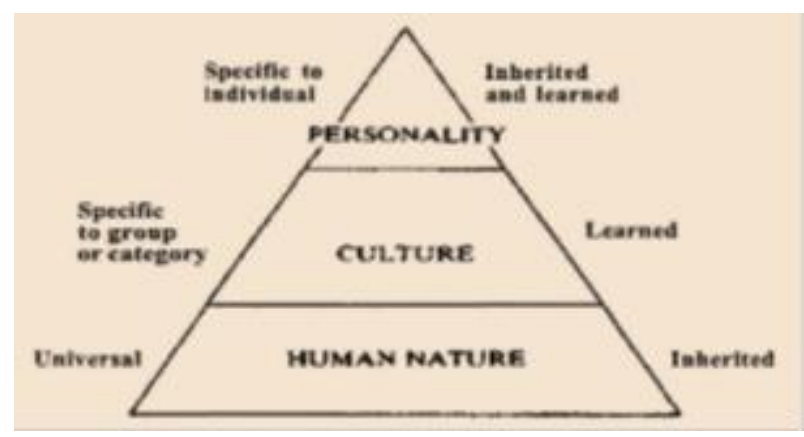

Sumber : Hosftede, 1991.
Gambar di atas menunjukan bagaimana budaya sebagai program mental pada sekelompok orang menjadi dasar bagi pembentukan personality dari orang-orang dalam kelompok tersebut.

$$
\text { Kreitner dan Kinicki }
$$
mendeskripsikan proses budaya mempengaruhi perilaku organisasi dengan dua cara. Para karyawan membawa budaya mereka ke tempat kerja dalam bentuk kebiasaan dan bahasa. Budaya organisasi yang merupakan produk dari budaya masyarakat mempengaruhi nilai-nilai individu, etika, sikap, anggapan, dan harapan. Budaya masyarakat dibentuk oleh faktor lingkungan yang beragam yang diurut di sebelah kiri pada gambar 2 .

Gambar 2.

Pengaruh Budaya Terhadap Perilaku Organisasi

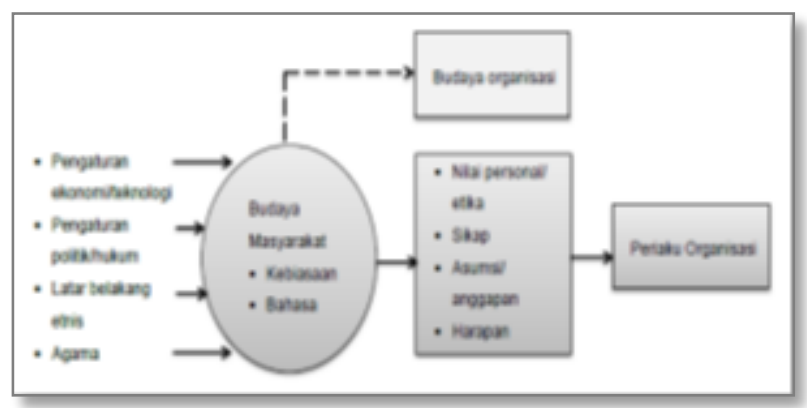

Sumber : Kreitner dan Kinicki (2014)

Indikator budaya yang sering digunakan dalam penelitian ilmiah dikembangkan oleh Hosftede (1991) sebagai hasil penelitian yang merupakan hasil perbandingan lintas budaya yang unik dari 116.000 karyawan IBM dari 53 negara (Kreitner dan Kinicki, 2014) yaitu:

1. Individualism-Collectivism. Individualisme merefleksikan sejauh mana individu mengharapkan kebebasan pribadi. Ini berlawan dengan kollektivisme (kelompok) yang didefinisikan menerima tanggungjawab dari keluarga, kelompok masyarakat (suku dll). 
2. Power distance. Didefinisikan sebagai jarak kekuasan antara pimpinan dan bawahan dalam hirarki organisasi adalah berbeda antara sejauh mana pimpinan dapat menentukan perilaku bawahan dan sebaliknya. Pada masyarakat yang power distance besar, adanya pengakuan tingkatan didalam masyarakat dan tidak memerlukan persamaan tingkatan. Sedangkan pada masyarakat yang power distance kecil, tidak mengakui adanya perbedaan dan membutuhkan persamaan tingkatan didalam masyarakat.

3. Uncertainty avoidance. Ketidakpastian mengenai masa depan adalah sebagai dasar kehidupan masyarakat. Masyarakat yang tingkat ketidakpastiannya tinggi akan mengurangi dampak ketidakpastian dengan teknologi, peraturan dan ritual. Sedangkan masyarakat dengan tingkat menghindari ketidak pastian yang rendah akan lebih santai sehingga praktik lebih tergantung prinsip dan penyimpangan akan lebih bisa ditoleransi.

4. Masculinity-femininity. Nilai maskulin menekankan pada nilai kinerja dan pencapaian yang nampak, sedangkan feminim lebih pada preferensi pada kualitas hidup, hubungan persaudaraan, modis dan peduli pada yang lemah.

Luthans (2005) mengungkapkan bahwa terdapat juga perbedaan dalam berbagai budaya nasional dan membuat generalisasi atau kesimpulan stereotip tidak hanya dapat menjadi suatu kesalahan, tapi juga dapat menjadi masalah. Indonesia sebagai negara dengan beragam budaya juga menjadi tantangan tersendiri dalam konteks perilaku organisasi. Pemimpin harus mampu mengelola karyawan dengan nilai-nilai individu yang berbeda karena perbedaan latar belakang budaya yang dianutnya. Nilai-nilai budaya ini diidentifikasikan Robbins dan Judge (2014) sebagai variabel independen pada tingkat individu dalam pendekatan perilaku organisasi yang dapat mempengaruhi perilaku karyawan.

Konsep etnis sering dikaitkan dengan budaya dan sering digunakan bergantian dengan budaya dan ras. Biasanya, etnis digunakan dalam referensi untuk kelompok dengan kebangsaan, budaya, atau bahasa yang sama. Konsep etnisitas terkait dengan konsep Yunani yakni ethnos, yang mengacu kepada orang-orang suatu bangsa atau suku, dan ethnikos, yang berarti nasional. Oleh karena itu, etnis mengacu pada kualitas etnis atau afiliasi dari kelompok, yang biasanya dicirikan dari segi budaya (Betancourt dan Lopez, 1993).

Kelompok etnis cenderung berinteraksi dengan kelompok etnis lain, interaksi tersebut tidak boleh diabaikan karena mungkin merupakan sumber pengaruh budaya. Oleh karena itu, adalah penting bahwa studi banding dari kelompok etnis mengidentifikasi dan mengukur variabel budaya yang diasumsikan bertanggung jawab dalam perbedaan yang diamati dalam fenomena psikologis sebelum perbedaan tersebut dikaitkan dengan budaya atas dasar keanggotaan kelompok (Betancourt dan Lopez, 1993). Upaya studi banding ini telah dilakukan dan ditemukan bahwa ada perilaku berbeda dari kelompok etnis tertentu walaupun diberi perlakuan yang sama (Cohen, 2006; Moorman dan Blakely, 2005; Ying Liu dan Cohen, 2010; Kwantes, et al., 2008). 


\section{BUDAYA MALUKU “PELA GANDONG”}

Pela gandong adalah pranata sosial bagi orang-orang di Maluku Tengah khususnya Pulau Seram, Ambon, dan Lease (Lokollo, et. al., 1997; Uneputty,1996). Sejak dahulu kala pranata sosial ini telah hidup dan berkembang sebagai suatu perekat hubungan-hubungan sosial di antara satu negeri dan negeri-negeri lain baik negeri yang beragama Islam maupun negeri yang beragama Kristen (Sahusilawane, 2004) dan berfungsi mengatur interaksi sosial masyarakat desa berpela dalam berbagai bidang (Uneputty, 1996).

\section{Pengertian Pela Gandong}

Secara sederhana pela dirumuskan sebagai ikatan persaudaraan antara dua desa atau lebih sedangkan gandong adalah hubungan persaudaraan antara dua desa atau lebih didasarkan atau dilatarbelakangi oleh adanya hubungan-hubungan genealogia antara desa-desa yang bersangkutan, dimana para leluhur dari desa-desa tersebut berasal dari keturunan yang sama, (Uneputty, 1996). Itulah sebabnya lasim pada desa-desa yang memiliki hubungan gandong, perkawinan antar warganya sangat terlarang.

Sahusilawane (2004) mengemukakan pendapat dari beberapa pakar budaya dan tokoh masyarakat tentang pengertian pela sebagai berikut ; 1) suatu ikatan atau hubungan persaudaraan atara seluruh penduduk dari dua desa atau lebih berdasarkan adat (Dr. Frank L. Cooley), 2) suatu perserikatan atau system persahabatan antara beberapa kampong atau negeri (Dr. Dieter Bartels), 3) ikatan kesatuan dan persaudaraan antara dua atau lebih negeri baik itu antar negeri-negeri Kristen atau negeri-negeri Islam maupun antar negeri-negeri Islam dan Kristen (Dr. Piet Tanamal), 4) pela adalah akronim dari pela, laha, dan luia artinya suatu perjanjian untuk kasih mengasihi karena sekandung atau seperti saudara kandung (J. E. Lokollo), 5) pela berasal dari kata pelania yang arinya sudah atau selsai, maksudnya sudah terjadi hubungan antara dua negeri yang terjadi karena yang satu membantu yang lain dalam peperangan atau dalam kepentingan negeri atau desa secara menyeluruh (Tomasoa Jokomina). Kutipan di atas menunjukan bahwa pela tidak dapat dipahami secara harafiah karena aspeknya cukup kompleks.

Kata gandong dalam bahasa Ambon dapat dibandingkan dengan kata kadung dalam bahsa Indonesia (Sahusilawane, 2004). Gandong atau kandung adalah Rahim atau satu pangkuan, suatu pusat dan awal dari pada segala sesuatu yang hidup. Jadi maksudnya adik dan kakak kandung mengikat perjanjian untuk kasih mengasihi.

Dengan demikian pela dan gandong mempunyai makna yang territorial dan makna yang geneologis. Dari sisi territorial pela dan gandong itu merupakan suatu perserikatan antara negeri-negeri sedangkan dari sisi geneologis pela dan gandong merupakan suatu persaudaraan sejati (Sahusilawane, 2004).

\section{Sejarah umum budaya Pela Gandong}

Asal mula pela baik bentuk, sifat, isi dan tatalaku ialah dari adanya kehidupan sosial yang berkembang di masyarakat Nunusaku di Pulau Seram (Lokollo et al, 1997). Perkembangan sosial masyarakat saat itu baik akibat pertambahan jumlah penduduk, dasar dan cara rumpun Patasiwa dan Patalima berpenampilan ataupun berbahasa mengakibatkan perpecahan masyarakat Nunusaku 
dan mendorong terjadinya eksodus, selain ke arah timur dan barat Pulau Nusa Ina itu sendiri (Pulau Seram), juga ke arah Pulau Ambon dan PulauPulau Lease. Dieter Bartels (dalam Uneputty, 1996) mengemukakan bahwa eksodus ini juga didorong oleh invasi orang-orang Barat khususnya Belanda yang berhasil melakukan politik devide at impera.

Selanjutnya peristiwa yang terjadi selama invasi Belanda (Uneputy, 1996) dimana ada bantuan yang diberikan satu negeri kepada negeri lainnya menjadi dasar dari suatu ikatan persekutuan pela, misalnya; bantuan yang diberikan dari berbagi negeri kepada Pattimura pada saat perang Pattimura ataupun kisah tentang hongi tochten (pelayaran hongi) dimana VOC mengerahkan armada kora-kora Bumi Putera yang diambil dari desa-desa tertentu di Pulau Ambon yang banyak ditolong warga desa Pulau Seram pada saat kehilangan arah. Sejalan dengan yang diungkapkan Sahusilawane (2004) bahwa pada masa penjajahan terutama di abad 17 dan 18 banyak negeri saling angkat pela dengan tujuan untuk saling membantu menghadapi perang melawan Belanda.

Sebagai contoh (Sahusilawane, 2004) Uli Hatuhaha di Pulau Haruku yang terdiri dari lima negeri masing-masing Pelau, kabau, Rohomoni, Kailolo, dan Hulaliu yang penduduknya beragama Islam (kecuali Hulaliu) bersama-sama dengan Kimelaha Leliato penguasa Ternate di jazirah Huamoal Seram Barat berperang melawan Belanda tahun 1637. Uli Hatuhaha mendapat bantuan dari negeri-negeri yang lain. Walaupun pada akhirnya perang itu dimenangkan oleh Belanda, tetapi setelah perang Uli Hatuhaha membuat atau angkat pela dengan pihak-pihak yang membantunya, yaitu dengan negeri Tuhaha di pulau Saparua, Oma di pulau Haruku dan Tihulale di pulau Seram. Suatu hal yang menarik di sini adalah pihak-pihak yang membantu Hatuhaha adalah negeri-negeri yang penduduknya bergama Kristen.

Kadang-kadang insiden atau akibat suatu bencana tertentu dapat pula membuat orang atau negeri membuat ikatan pela. Ketika terjadi bencana gempa bumi atau dikenal dengan istilah tanah goyang di negeri Elpaputih di Seram Selatan, banyak orang Ihamahu dari Pulau Saparua yang sedang mengusahakan kayu untuk membangun gereja yang menjadi korban di laut. Ada sebagian yang selamat dan ditolong oleh orang-orang di negeri Amahai yang kemudian membantu menyelesaikan pembangunan gedung gereja. Sebagai tanda adanya pertolongan dari negeri Amahai maka diadakanlah ikatan pela antara negeri Ihamahu di Pulau Saparua dan negeri Amahai di Pulau Seram (Sahusilawane, 2004).

\section{Latar Belakang te rjadinya Pela Gandong}

Ada beberapa alasan terjadinya hubungan pela sebagai sebuah tradisi sebagaimana disebutkan oleh para ahli (Uneputy, 1996; Bartels, 1977 dalam Ralahallo 2012; Sahusilawane, 2004), antara lain: pertama, hubungan pela sebagai balas jasa dari negeri yang satu kepada negeri yang lain yang pernah membantunya pada saat ada peperangan ataupun bencana alam. Kedua, hubungan pela sebab ada hubungan persaudaraan antara negeri yang bersangkutan menurut cerita dari datuk-datuk mereka, bahwa mereka adalah saudara kandung. Ketiga, hubungan pela sebab terjadinya hal-hal yang luar biasa. Adapun kekuatan mengikat perjanjian pela (Hukum Pela) 
didasarkan pada asas "sei hale hatu, hatu hale sel". Dapat diterjemahkan "sapa bale batu, batu bale dia" yang bermakna "apa yang tua-tua bikin, harus dipelihara".

Ada empat hal pokok yang mendasari pela gandong yaitu: negeri-negeri yang berpela berkewajiban untuk saling membantu pada kejadian genting (perang, bencana alam). Apabila diminta, maka negeri yang satu wajib memberikan bantuan kepada negeri lain, misalnya hendak melaksanakan proyek kepentingan umum seperti pembangunan sekolah, masjid, atau gereja. Apabila seseorang sedang mengunjungi negeri yang berpela itu, maka orang-orang di negeri itu wajib untuk memberi makanan kepadanya dan tamu yang sepela itu tidak perlu meminta izin untuk membawa pulang hasil bumi atau buah-buahan yang menjadi kesukaannya, karena penduduk negeri-negeri yang berhubungan pela itu dianggap sedarah, maka dua orang yang sepela tersebut dilarang untuk menikah. Bagi orang-orang yang melanggar segala ketentuan tersebut, konon katanya akan mendapatkan hukuman dari nenek moyang yang mengikrarkan pela.

\section{Macam-macam pela}

Menurut Cooley (1987 dalam Ralahallo 2012), pela dibagi dalam dua kategori yaitu 1) pela keras/pela tuni/pela tulen/pela batu karang/pela darah terjadi oleh karena dibentuk atas dasar 'minum darah' sebagai pengesahan hubungan pela tersebut. 2) pela tempat sirih dibentuk dengan menyuguhkan sirih pinang sebagai suatu tradisi dalam masyarakat Alifuru. Bartels (1977 dalam Ralahallo 2012) menambahkan pela gandong (atau bungso) berdasarkan ikatan turunan artinya satu atau lebih banyak mata rumah dalam negeri-negeri yang berpela itu, menganggap diri sebagai satu turunan. Upaya mempertahankan tradisi pela dilakukan melalui ritual panas pela yang bertujuan untuk menjaga kelestarian hubungan persaudaraan sebagai nilai dasar pela.

\section{PELA GANDONG SEBAGAI PROSES BUDAYA}

Kreitner dan Kinicki (2014a)

mengungkapkan bahwa proses budaya mempengaruhi perilaku organisasi antara lain dengan cara karyawan membawa budaya mereka ke tempat kerja dalam bentuk kebiasaan dan bahasa yang juga mempengaruhi nilai-nilai individu, etika, sikap, anggapan, dan harapan. Sejalan dengan pendapat Hofstede (1991) yang menunjukan bahwa budaya sebagai program mental pada sekelompok orang menjadi dasar bagi pembentukan kepribadian dari orang-orang dalam kelompok tersebut.

"Pela gandong" merupakan proses budaya sehingga dapat mempengaruhi kepribadian dan nilai-nilai individu seseorang di tempat kerjanya. Sistim kekerabatan yang dibangun berdasarkan nilai-nilai pela gandong menurut Uneputty (1996) telah mampu membentuk jati diri manusia Maluku apa yang disebut common sence of belonging (rasa kebersamaan), common sence of unity (rasa persatuan dan kesatuan), common sense of responsibility (rasa tanggung jawab). Nilai-nilai inilah yang diharapkan mampu mempengaruhi perilaku individu di tempat kerjanya.

\section{SIMPULAN}

Budaya berdasarkan pemaparan di atas merupakan faktor ekternal yang mampu mempengaruhi perilaku organisasi. Budaya lokal 
Maluku "Pela Gandong" sebagai salah satu bentuk budaya yang dijunjung penganutnya dalam pendekatan tersebut juga diduga mampu mempengaruhi perilaku organisasi. Mengingat saat ini belum ada kajian manajerial yang melibatkan Pela Gandong, maka diharapkan tulisan ini dapat menjadi awal bagi pengembangan penelitian di masa mendatang.

\section{DAFTAR PUSTAKA}

Ang, S., Van Dyne, L. dan Begley, T. M. 2003. The Employment Relationship of Foreign Workers versus Local Employees: a Field Study of Organizational Justice, Job Satisfaction, Performance, and OCB. Journal of Organizational Behavior, 24:561583.

Azis, N. A., Mangoting, Y., dan Lutfillah, N. Q., 2015. Memaknai Independensi Auditor Denan Keindahan Nilai-Nilai Kearifan Lokal Siri'na Pacce. Jurnal Akuntansi Multiparadigma, 6(1)145-156

Bakker, A. B., dan Schaufei, W. B., 2008. Positive organizational behavior: Engaged employees in flourishing organization. Journal of Organizational Behavior, 29:147-154.

Betancourt, H. dan Lopez, R. 1993. The study of Culture, Etnicity, and Race in American Psychology. American Psychologist, 48(6):629-637.

Cohen, A. 2006. The Relationship Between Multiple Commitments and Organizational Citizenship Behavior in Arab and Jewish Culture. Journal of Vocational Behavior, 69:105-1118

Frost, N., 2004. Adat di Maluku: Nilai Baru atau Eksklusivisme Lama?. Antropologi Indonesia, 74:1-11

Hoedodo, T.S.B., Surjo, J., Qodir, Z., 2013. Local Political Conflict and Pela Gandong Admist the Religious Conflict. Journal of Government and Politics, 4(2):336-349
Hofstede, G. 1991. Cultures and Organisations, Software of the Mind. Intercultural cooperation and its importance for survival. London:McGraw-Hill Book Company.

Hudaya, Z. A., dan Nugroho, S. W. D., 2013. Kearifan Lokal Budaya Jawa Sebagai Basis Model Kepemimpinan Yang Efektif. Journal \& Proceeding Fakultas Ekonomi dan Bisnis Unsoed, volume 3, nomor 1.

Huwae, S., 1995. Divided Opinions About Adat Pela: A Study Og Pela Tamilouw-SiriSoriHutumuri. Cakalele, 6:77-92

Jean, L. C. 2013. Diversity eadership: Influence of Etnicity, Gender, and Minority Status. Open Journal of Leadership. 2(1):1-10

Kadir H. A. 2012. Sapa Bale Batu, Batu Bale Dia; Politik Revivalisme; Tradisi Siwalima Orang Ambon Pasca Konflik. Lakon, Jurnal Kajian Sastra dan Budaya, 1(1):61-75.

Kambu, A., Troena, E.A., Surachman dan Setiawan,M. 2012. Influence of LeaderMember Exchange, Perceived Organizational Support, Papua Etnic Culture and Organizational Citizenship Behavior toward Employee Performances of Workers in Papua Provincial Secretary Office. Journal of Business and Management, 5(4):31-38.

Kreitner, R. dan Kinicki, A. 2014. Perilaku Organisasi - Organizational Behaviour. Edisi 9, Buku 1. Jakarta : Salemba Empat.

Kwantes, C.T., Karam C.M., Kuo B.C.H. dan Towson S. 2008. Culture's influences on the perception of OCB as in-role or extra-role. International Journal of Intercultural Relations, 32:229-243

Lam, S.S.K., Schaubroech, J. dan Aryee, S. 2002. Relationship between Organizational Justice and Employee Work Outcome: A CrosssNational Study. Journal of Organizational Behavior, 23(1):1-18

Lokollo, J. E., Pattiruhu, C. M., Lestaluhu, M., Timisela, Iz., Limahelu, D., Limahelu, L., Leatemia, J., Leasa G., 1997. Seri Budaya 
Pela Gandong dari Pulau Ambon. Ambon: Lembaga Kebudayaan daerah Maluku.

Luthans, F. 2005. Perilaku Organisasi. Edisi sepuluh. New York: McGraw-hill.

Manuhutu, R., Purwiyastuti, W., dan Widiarto, T., 2015. Budaya Pela Gandong Di Negeri Haria Sebagai Alat Pemersatu Dan Perdamaian Orang Maluku Tengah. Widyasari, 17(2):100-105

Marimuthu, M. dan Kolandaisamy I. 2009. Ethnic and Gender Diversity in Boards of Directors and Their Relevance to Financial Performance of Malaysian Companies. Journal of Sustainable Development, 2(3):139-148.

Matitaputty, J. K., 2013. Pendidikan Karakter Melalui Penggalian Nilai-Nilai Kearifan Lokal budaya Pela Gandong Di Maluku. Jurnal Pendidikan "Jendela Pengetahuan", 6(15):73-80.

Moorman, R. H. dan Blakely, G. L. 1995. Individualism-collectivism as an Individual Difference Predictor of Organizational Citizenship Behavior. Journal of Organizational Behavior, 16:127-142.

Mualim, Awang, J., dan Abu Bakar, I., 2014. Pela Gandong Sebagai Pemangkin Toleransi Antara Muslim dan Kristian di Ambon. Jurnal Hadjari, 6(1):43-55.

Ngo, Hang-yue, Foley, S. dan Loi, R. 2006. The Effect of Culutral Types on Perceptions of Justice and Gender Inequity in the Workplace. International Journal of Human Resources Management, 17:983-998

Pattiselanno, J.Th.F., 1999. Tradisi Uli, Pela dan Gandong Pada Masyarakat Seram, Ambon, dan Uliase. Antropologi Indonesia, 58:58-69

Piris, S. dan Tilaar, S. 2014. Graha Wisata Adat Pela Gandong di Maluku (Simbiosis Mutualisme).

Putera, I. D. G. W., dan Supartha, W. G., 2014. Penerapan Konsep Tri Hita Karana Dalam Hubungannya Dengan Budaya Organisasi
Di rektorat Unud. E-Jurnal Manajemen universitas Udayana, 3(7):1999-2014.

Ralahallo, R.N. 2009. Kultur Damai Berbasis Tradisi Pela Dalam Perspektif Psikologis Sosial. Jurnal Psikologi, 36(2):177-188

Riana, I. G., 2011. Dampak Penerapan Kultur Lokal Tri Hita Karana Terhadap Orientasi Kewirausahaan dan Orientasi Pasar. Jurnal Teknik Industri, 13(1)37-44

Robbins, Stephen P., 2006. Perilaku Organisasi, PT Indeks, Kelompok Gramedia, Jakarta.

Robbins, S.P. dan Judge, T. A. 2014. Perilaku Organisasi - Organizational Behaviour. Buku 1, Edisi 12. Jakarta : Salemba Empat.

Sahusilawane, F. 2004. Sejarah Lahirnya Pela dan Gandong Antar Negeri-negeri Di Pulau Ambon. Laporan Penelitian Sejarah dan Nilai Tradisional Ambon. Ambon : Balai Kajian Sejarah dan Nilai Tradisional Ambon.

Sholeh, B., 2013. The Dynamics of Muslim and Christian Relatioins in Ambon, Easter Indonesia. International Journal of Bussines and School Sciences, 4(3):303-311.

Siswanto, T., dan Najih, M., 2015. Pengaruh Kearifan Lokal Dalam Berbagi Pengetahuan di Perusahaan Jawa Tengah. Prosiding Seminar Nasional Sistim Informasi Indonesia, 2-3 November 2015.

Stone, D. L., dan Deadrick, D. L., 2015. Challenges and Opprtunity Affecting the Human Resource Management. Human Resource Management Review, 25:139-145

Tuhuteru, L., 2014. Pembinaan Nilai-Nilai Demokrasi Dalam Budaya Lokal Pada Masyarakat Pasca Konflik Sosial Ambon. Jurnal Pendidikan "Jendela Pengetahuan", 7(17):29-39

Tsui, A. S., Nifadkar, S. S., dan Amy Yi Ou., 2007. Cross-National, Cross- Cultural Organizational Behavior Research : Advances, Gaps, and Recommendations. Journal of Management, 33:426-478. 
Uneputty, T. J. A. 1996. Perwujudan Pela Dalam Kehidupan Sosial Masyarakat Maluku. Ambon: Bagian Proyek Pengkajian dan Pembinaan Nilai-nilai Budaya Maluku.

White, R. D., 1999. Managing the Diverse Organization: The Imperative for a New Multiculture Paradigm. Public Administration \& Management: An Interactive Journal, 4 (4):469-493

Ying, Liu. Dan Cohen, A. 2010. Values, commitment, and OCB among Chinese employees. International Journal of Intercultural Relations, 34:493-506 
